\title{
Gambaran Kepuasan Pasien yang Menggunakan Jaminan Kesehatan (BPJS) terhadap Mutu Pelayanan Keperawatan di Rumah Sakit Kabupaten Jember
}

\section{(Description of BPJS Patient Statisfaction with The Quality of Nursing Service at The Hospital Jember Regency)}

\author{
Kurnia Rahmawati, Anisah Ardiana, Dicky Endrian Kurniawan \\ Fakultas Keperawatan Universitas Jember \\ Jl.Kalimantan No.37, Kampus Tegalboto Jember Telp./Fax(0331) 323450 \\ E-mail: niarahmaw272@gmail.com
}

\begin{abstract}
Quality of service is a service that suits your needs, affordable, effective, efficient, and no risk to save on expenses. This study aimed to analyze the description of BPJS patient satisfaction with the quality of nursing service at inpatient ward of hospital in Jember. This was a cross sectional study. The subjects of this study were BPJS patients at inpatient ward at hospital in Jember. There were 120 respondents choosed by purposive sampling. Data were collected using the Patient Satisfaction with Nursing Care Quality Questionnaire (PNSCQQ). This study showed that the patient satisfaction is not optimal. Indicators of general perception of patients in each statement showed that 80 patients (63.5\%) said the overall quality of health service received was good. The overall quality of nursing service was also said to be good by 80 patients (63.5\%). As many as 90 patients (71.5\%) agreed that they wanted to recommend one of the hospital in Jember to family and friends who needed help in terms of health service. This research showed that it is important to improve the quality of nursing service to increase patient satisfaction. Nurses need to improve nursing care. This research can be used as a reference and illustration for hospital management, and nurses are expected to implement and improve quality nursing service in order to achieve better health service so patient satisfaction will be increase.
\end{abstract}

Keywords: Nurses, Patient Satisfaction, Quality of Nursing Service

\begin{abstract}
Abstrak
Kualitas pelayanan merupakan pelayanan yang sesuai dengan kebutuhan, terjangkau, efektif, efisien, dan tidak ada risiko untuk menghemat pengeluaran. Penelitian ini bertujuan untuk menganalisis gambaran kepuasan pasien BPJS terhadap kualitas pelayanan keperawatan di ruang rawat inap rumah sakit Kabupaten Jember. Penelitian ini menggunakan desain deskriptif dengan pendekatan cross sectional. Responden adalah 120 pasien BPJS di ruang rawat inap rumah sakit Kabupaten Jember, yang dipilih menggunakan purposive sampling. Data dikumpulkan menggunakan Kuesioner Kepuasan Pasien yaitu Patient Satisfaction with Nursing Care Quality Questionnaire (PNSCQQ). Penelitian ini menunjukkan bahwa kepuasan pasien tidak optimal. Indikator persepsi umum pasien dalam setiap pernyataan menunjukkan bahwa 80 pasien (63,5\%) mengatakan keseluruhan kualitas layanan kesehatan yang diterima baik. Kualitas keseluruhan layanan keperawatan juga dikatakan baik oleh 80 pasien (63,5\%). Sebanyak 90 pasien $(71,5 \%)$ setuju bahwa mereka ingin merekomendasikan salah satu rumah sakit di Kabupaten Jember kepada keluarga dan teman-teman yang membutuhkan bantuan dalam hal layanan kesehatan. Penelitian ini menunjukkan bahwa penting untuk meningkatkan kualitas pelayanan keperawatan agar kepuasan pasien meningkat. Perawat perlu meningkatkan asuhan keperawatan. Penelitian ini dapat digunakan sebagai referensi dan gambaran untuk manajemen rumah sakit, dan perawat yang dapat digunakan untuk menerapkan dan meningkatkan pelayanan keperawatan yang berkualitas untuk mencapai layanan kesehatan yang lebih baik sehingga kepuasan pasien akan meningkat.
\end{abstract}

Kata Kunci: Perawat, Kepuasan Pasien, Mutu Pelayanan Keperawatan 


\section{Pendahuluan}

Nilai dari kepuasan pasien terhadap pelayanan kesehatan merupakan komponen utama dari rumah sakit yang bermutu [1]. Pelayanan keperawatan merupakan faktor penentu dalam pengukuran kepuasan pasien [2] Kepuasan pasien terhadap pelayanan keperawatan dapat dinilai dari kenyataan pelayanan keperawatan selama dirawat di rumah sakit sesuai dengan keinginan pasien terhadap pelayanan keperawatan [3]. Pengukuran kepuasan pasien dapat dilakukan dengan cara mengidentifikasi indikator yang mempengaruhi perawatan meliputi assurance, reliability, responsiveness, dan empathy serta menentukan item mana yang harus diprioritaskan atau yang membutuhkan perubahan dalam pelayanan keperawatan [4]. Pengukuran kepuasan pasien juga dapat dilakukan dengan cara mengukur persepsi pasien terhadap kualitas pelayanan secara keseluruhan dan keinginan pasien untuk merekomendasikan pelayanan kesehatan tersebut kepada orang lain [5].

Kepuasan pasien dapat dipengaruhi oleh asuransi atau jaminan kesehatan [6]. Salah satu bentuk asuransi kesehatan yang digunakan oleh masyarakat Indonesia adalah BPJS (Badan Penyelenggara Jaminan Sosial) Kesehatan. Pasien BPJS merupakan pasien yang melakukan pembayaran dengan bantuan program jaminan kesehatan dari Pemerintah [7]. Penelitian lain yang telah dilakukan di Rumah Sakit Daerah Balung menunjukkan bahwa pemberian informasi kepada pasien BPJS masih kurang. Kemampuan perawat dalam menjaga kesopanan saat melakukan tindakan keperawatan kepada pasien BPJS masih banyak dikeluhkan. Sikap empati yang diberikan oleh perawat dalam memberikan tindakan keperawatan kepada pasien BPJS masih dirasa kurang memuaskan [8]. Hal tersebut mempengaruhi kepuasan pasien BPJS terhadap pelayanan keperawatan. Berdasarkan uraian di atas, tujuan penelitian ini adalah mengidentifikasikan kepuasan pasien BPJS terhadap mutu pelayanan keperawatan di salah satu rumah sakit Kabupaten Jember.

\section{Metode Penelitian}

Penelitian ini termasuk penelitian
kuantitatif dengan menggunakan analisis deskriptif. Penelitian dilaksanakan di tiga ruang rawat inap di salah satu rumah sakit Kabupaten Jember dimulai sejak bulan September sampai Oktober 2019. Teknik pengambilan sampel penelitian menggunakan purposive sampling yang melibatkan 126 pasien sebagai responden penelitian. Data penelitian dikumpulan menggunakan the Patient Satisfaction with Nursing Care Quality Questionnaire (PNSCQQ) yang telah diterjemahkan dalam Bahasa Indonesia. PNSCQQ terdiri dari 22 pernyataan, setelah dilakukan uji validitas dengan $r$ tabel senilai 0,444 terdapat 18 pernyataan valid meliputi 5 indikator yaitu assurance, reliability, responsiveness, empathy, dan persepsi umum pasien. Hasil reliabilitas dari kuesioner dengan nilai Cronbach's Alpha sebesar 0,949 yang menunjukkan bahwa kuesioner yang dipakai dalam penelitian sangat reliable.

\section{Hasil Penelitian}

\section{Data Karakteristik Responden}

Karakteristik data pribadi pasien yang dirawat di tiga ruang rawat inap meliputi usia, lama dirawat, jenis kelamin, status perkawinan, pendidikan terakhir, dan pekerjaan. Gambaran distribusi responden dapat dilihat pada tabel 1 dan tabel 2.

Tabel 1 : Distribusi Responden Berdasarkan Usia dan Lama Dirawat $(n=126)$

\begin{tabular}{lcccc}
\hline Variabel & Mean & $\begin{array}{c}\text { Medi } \\
\text { an }\end{array}$ & Min & Maks \\
\hline $\begin{array}{l}\text { Usia } \\
\text { tahun) }\end{array}$ & 50,65 & 53 & 18 & 81 \\
\hline $\begin{array}{l}\text { Lama } \\
\text { Dirawat } \\
\text { (hari) }\end{array}$ & 3,45 & 3 & 1 & 10 \\
$\begin{array}{l}\text { Sumber : data primer yang diolah, 2019 } \\
\text { Sumb }\end{array}$
\end{tabular}

Sumber : data primer yang diolah, 2019

Tabel 2 : Distribusi Responden Berdasarkan Jenis Kelamin, Status Perkawinan, Pendidikan terakhir, dan pekerjaan $(n=126)$

\begin{tabular}{lcc}
\hline \multicolumn{1}{c}{ Variabel } & Frekuensi & Persentase \% \\
\hline Jenis Kelamin & & \\
Laki-laki & 64 & 50,8 \\
Perempuan & 62 & 49,2 \\
Status Perkawinan & & \\
Menikah & 97 & 77,0 \\
Belum Menikah & 18 & 14,3 \\
Duda/Janda & 11 & 8,7 \\
\hline
\end{tabular}




$\begin{array}{lcc}\text { Pendidikan } & & \\ \text { Terakhir } & 8 & 6,4 \\ \text { Tidak Sekolah } & 31 & 24,6 \\ \text { SD } & 15 & 11,9 \\ \text { SMP } & 46 & 36,5 \\ \text { SMA } & 26 & 20,6 \\ \text { Perguruan Tinggi } & & \\ \text { Pekerjaan } & & \\ \text { PNS } & 16 & 12,7 \\ \text { TNI } & 7 & 5,5 \\ \text { Pekerja } & 4 & 3,2 \\ \text { Pemerintah Non } & 20 & 15,9 \\ \text { PNS } & 23 & 18,2 \\ \text { Pekerja Swasta } & 7 & 5,5 \\ \text { Wiraswasta } & 11 & 8,7 \\ \text { Petani } & 38 & 30,2 \\ \text { Pelajar } & \\ \text { Tidak Bekerja } & & \\ \text { Sumber : Data Primer yang diolah, 2019 }\end{array}$

Responden pada penelitian ini rata-rata berusia 50,65 tahun dengan usia min-maks 1881 tahun. Lama dirawat responden rata-rata selama 3,45 hari dengan lama perawatan minmaks 1-10 hari. Paling banyak responden berjenis kelamin laki-laki yaitu sebanyak 64 paien $(50,8 \%)$. Responden paling banyak memiliki status perkawinan menikah yaitu sebanyak 97 pasien (77\%). Pendidikan terakhir responden paling banyak adalah SMA sebanyak 46 pasien $(36,5 \%)$. Sedangkan responden paling banyak tidak bekerja pada status pekerjaan sebanyak 38 pasien $(30,2 \%)$.

\section{Data Kepuasan Pasien}

Kepuasan pasien BPJS terhadap pelayanan keperawatan di tiga ruang rawat inap di salah satu rumah sakit Kabupaten Jember menghasilkan data tentang kepuasan pasien dan persepsi umum pasien. Hasil penelitian tentang kepuasan pasien dapat dilihat pada tabel 3.

Tabel 3: Kepuasan Pasien BPJS terhadap Pelayanan Keperawatan

\begin{tabular}{lcccc}
\hline \multicolumn{1}{c}{ Variabel } & Mean & Median & Min & Maks \\
\hline Kepuasan & 49,60 & 48,00 & 36 & 70 \\
Pasien BPJS & 46 & \\
\multicolumn{4}{l}{ Sumber : data } & primer yang diolah, 2019
\end{tabular}

Tabel di atas menunjukkan bahwa nilai mean (rata-rata) kepuasan pasien sebesar 49,60, nilai tengah sebesar 48 , nilai minimal sebesar 36 dan nilai maksimal sebesar 70. Penelitian ini menunjukkan bahwa hasil nilai mean kepuasan pasien BPJS tidak mendekati ke arah nilai maksimal 70, akan tetapi telah melewati nilai tengah 48. Sehingga dapat dikatakan bahwa kepuasan pasien tidak maksimal.

Selain kepuasan pasien yang terdiri dari empat indikator, persepsi umum pasien juga termasuk indikator yang diukur untuk mengukur kepuasan pasien. Hasil penelitian tentang persepsi umum pasien terdiri dari tiga pernyataan. Pernyataan tersebut yaitu kepuasan pasien terhadap keseluruhan kualitas pelayanan kesehatan selama dirawat di rumah sakit, kepuasan pasien terhadap keseluruhan kualitas pelayanan keperawatan selama dirawat di rumah sakit dan keinginan untuk merekomendasikan kepada keluarga dan teman.

Tabel 4 : Distribusi Frekuensi dan Persentase Persepsi Umum Pasien Masing-Masing Pernyataan $(n=126)$

\begin{tabular}{|c|c|c|c|c|}
\hline Pernyataan & $\begin{array}{c}\mathbf{S} \\
\mathbf{F} \\
(\%)\end{array}$ & $\begin{array}{c}\text { B } \\
F(\%)\end{array}$ & $\begin{array}{c}\text { SB } \\
\text { F (\%) }\end{array}$ & $\stackrel{\text { I }}{F(\%)}$ \\
\hline $\begin{array}{l}\text { Kualitas pelayanan } \\
\text { kesehatan } \\
\text { Kualitas pelayanan } \\
\text { keperawatan }\end{array}$ & $\begin{array}{c}5 \\
(4,0) \\
6 \\
(4,8)\end{array}$ & $\begin{array}{c}80 \\
(63,5) \\
80 \\
(63,5) \\
\end{array}$ & $\begin{array}{c}29 \\
(23,0) \\
30 \\
(23,8)\end{array}$ & $\begin{array}{c}12 \\
(9,5) \\
10 \\
(7,9) \\
\end{array}$ \\
\hline Pernyataan & & $\begin{array}{c}\text { AS } \\
\text { F (\%) }\end{array}$ & $\begin{array}{c}\mathbf{S} \\
\mathbf{F}(\%)\end{array}$ & $\begin{array}{c}\text { SS } \\
F(\%)\end{array}$ \\
\hline $\begin{array}{l}\text { Keinginan } \\
\text { merekomendasikan } \\
\text { rumah sakit ke } \\
\text { keluarga dan } \\
\text { teman-teman }\end{array}$ & & $\begin{array}{c}8 \\
(6,3)\end{array}$ & $\begin{array}{c}90 \\
(71,5)\end{array}$ & $\begin{array}{c}28 \\
(22,2)\end{array}$ \\
\hline
\end{tabular}

Sumber: Data Primer, Oktober 2019

Tabel di atas menggambarkan distribusi frekuensi dan persentase persepsi umum pasien masing-masing pernyataan berdasarkan kuesioner PSNCQQ. Hasil data indikator persepsi umum pasien menunjukkan bahwa 80 pasien (63,5\%) mengatakan keseluruhan kualitas pelayanan kesehatan yang diterima bagus. Keseluruhan kualitas pelayanan keperawatan juga dikatakan bagus oleh 80 pasien $(63,5 \%)$. Sebanyak 90 pasien $(71,5 \%)$ mengatakan setuju ingin merekomendasikan salah satu rumah sakit di Kabupaten Jember kepada keluarga dan teman-teman yang membutuhkan bantuan dalam hal pelayanan kesehatan.

\section{Pembahasan}

\section{Gambaran Karakteristik Responden}

Usia responden pasien BPJS yang dirawat di rumah sakit menghasilkan nilai mean (ratarata) 50,65 tahun, usia ini termasuk dalam tahap 
perkembangan masa dewasa tengah. Hasil dari penelitian ini sesuai dengan penelitian lain yang menunjukkan bahwa usia rata-rata pasien yang dirawat di rumah sakit adalah 43,7 tahun, usia ini juga termasuk dalam tahap perkembangan masa dewasa tengah [9]. Masa dewasa tengah yaitu kisaran usia 40-60 tahun [10]. Peneliti berasumsi bahwa pasien yang dirawat di rumah sakit, paling banyak berada dalam rentang usia dewasa tengah dan termasuk dalam usia produktif.

Distribusi responden yang dirawat di rumah sakit mempunyai nilai mean (rata-rata) selama 3,45 hari. Hasil dari penelitian sesuai dengan penelitian lain yang menghasilkan data bahwa lama perawatan pasien paling banyak adalah 78 orang (78\%) dirawat selama 2-6 hari [11]. Lama pasien dirawat dilihat dari jenis penyakit, kondisi fisik, penerimaan diri pasien terhadap penyakitnya, dan kestabilan dalam menerima pengobatan dan perawatan yang ditentukan oleh tim medis selama dirawat di rumah sakit [11]. Peneliti berasumsi bahwa pasien dirawat di rumah sakit kurang lebih selama seminggu. Lama tidaknya pasien dirawat di rumah sakit ditentukan oleh tim medis yang melihat status kesehatan pasien.

Hasil dari penelitian menunjukkan bahwa sebanyak 64 pasien $(50,8 \%)$ pasien BPJS lebih banyak berjenis kelamin laki-laki. Penelitian lain yang menunjukkan bahwa paling banyak responden dengan jenis kelamin perempuan yaitu sebesar 53 pasien (53,0\%) [11]. Sedangkan penelitian lainnya menunjukkan bahwa responden paling banyak dengan jenis kelamin laki-laki yaitu sebanyak 135 pasien (54\%) [9]. Setiap pasien memiliki pandangan terhadap jasa atau pelayanan yang telah diterima. Perempuan lebih banyak melihat penampilan dan pelayanan kesehatan secara detail. $^{12}$ Perempuan lebih sadar akan kebersihan dan keterampilan perawat yang kurang. Perempuan lebih kritis terhadap aspek kualitas perawatan ketika mengevaluasi kinerja staf. $^{2}$ Peneliti berasumsi bahwa perbandingan jumlah pasien yang dirawat di rumah sakit antara pasien laki-laki dengan pasien perempuan tidak jauh berbeda. Pasien perempuan lebih kritis dalam menilai mutu pelayanan keperawatan yang telah diberikan.

Hasil dari penelitian yang telah dilakukan menunjukkan bahwa pasien paling banyak memiliki pendidikan terakhir SMA yaitu sebanyak 46 (36,5\%). Penelitian ini tidak sesuai dengan hasil penelitian lain yang menghasilkan data $32 \%$ responden dengan status pendidikan e-Journal Pustaka Kesehatan, vol. 8 (no. 2), Mei 2020 dasar [2]. Pasien yang memiliki pendidikan tinggi dapat mengakses informasi tentang tugas dan tanggung jawab perawat. Pasien dengan keterbatasan pendidikan akan lebih pasif dan kurang kritis terhadap pelayanan yang telah diberikan oleh perawat [2]. Peneliti berasumsi bahwa pasien BPJS dalam penelitian paling banyak memiliki tingkat pendidikan menengah ke atas. Perbedaan tingkat pendidikan akan menghasilkan perbedaan penilaian pula terhadap pelayanan keperawatan yang telah diberikan.

Distribusi responden yang dirawat di rumah sakit paling banyak memiliki status perkawinan menikah yaitu sebanyak 97 pasien $(77,0 \%)$. Penelitian ini sesuai dengan penelitian lain bahwa mayoritas responden memiliki status perkawinan menikah sebanyak 150 pasien (60\%) [9]. Pasien yang telah menikah memiliki semangat untuk sembuh karena dukungan kesehatan dan sosial dari suami atau istri yang menjaga [13]. Peneliti berasumsi bahwa pasien BPJS di salah satu rumah sakit Kabupaten Jember paling banyak memiliki dukungan kesehatan dan dukungan sosial dari suami atau istri. Dukungan kesehatan dan sosial akan berdampak pada semangat pasien BPJS agar pemulihan kesehatan lebih cepat.

Frekuensi status pekerjaan pasien paling banyak tidak bekerja yaitu sejumlah 38 pasien $(30,2 \%)$. Berdasarkan penelitian lain menghasilkan data paling banyak tidak bekerja sebanyak 28 responden (57,1\%) [14]. Pasien yang bekerja akan lebih menuntut dan mengkritik pelayanan yang diterima. Hal ini dipengaruhi oleh faktor pendidikan dan pemahaman pasien tentang pelayanan kesehatan yang diterima [15]. Peneliti berasumsi bahwa dalam penelitian ini pasien BPJS paling banyak tidak bekerja dikarenakan status pendidikan pasien paling banyak SMA, hal ini juga akan mempengaruhi pandangan pasien terhadap pelayanan keperawatan.

\section{Kepuasan Pasien BPJS terhadap Pelayanan Keperawatan}

Hasil penelitian kepuasan pasien BPJS menunjukkan bahwa nilai mean (rata-rata) pasien sebesar 49,60 dengan nilai minimal 36 dan nilai maksimal 70 . Penelitian ini menunjukkan bahwa hasil nilai mean kepuasan pasien BPJS tidak mendekati ke arah nilai maksimal 70 , akan tetapi telah melewati nilai tengah 48. Sehingga dapat dikatakan bahwa kepuasan pasien tidak maksimal. Hasil penelitian berbeda dengan penelitian lain yang 
menunjukkan bahwa terdapat 73 pasien $(73,0 \%)$ merasa puas terhadap pelayanan keperawatan [11]. Hasil penelitian lain yang telah dilakukan menyatakan bahwa mutu pelayanan keperawatan memiliki nilai rata-rata sebesar $64,21(66,9 \%)$ dengan nilai minimal 55 dan nilai maksimal 70 yang berarti mutu pelayanan keperawatan sudah cukup baik [8].

Berdasarkan hasil penelitian di atas dapat disimpulkan bahwa kepuasan pasien BPJS terhadap pelayanan kesehatan meskipun tidak maksimal akan tetapi telah melewati nilai tengah. Semakin tinggi kualitas pelayanan kepada pasien BPJS, maka semakin tinggi pula tingkat kepuas pasien BPJS [16]. Pemberian pelayanan kesehatan harus berlaku bagi semua anggota masyarakat yang membutuhkan pelayanan kesehatan tanpa membedakan status ekonomi (termasuk pasien yang menggunakan pembayaran BPJS), sosial, geografis, dan agama pasien [17]. Berdasarkan penelitian tersebut peneliti berasumsi bahwa penelitian ini menghasilkan kepuasan pasien yang tidak maksimal dikarenakan masih ada beberapa pasien yang menilai pelayanan keperawatan kurang dan sedang dalam beberapa item pernyataan kualitas pelayanan terhadap pasien BPJS. Oleh karena itu mutu pelayanan keperawatan perlu diperhatikan dan ditingkatkan agar kepuasan pasien maksimal. Berdasarkan hasil penelitian kepuasan pasien BPJS berdasarkan tiap pernyataan dan tiap indikator, pasien BPJS paling banyak menilai bagus di tiap-tiap item pernyataan.

Berdasarkan hasil penelitian tiap indikator, telah diketahui bahwa indikator mutu pelayanan kesehatan akan berdampak terhadap kepuasan pasien BPJS. Hasil ini sejalan dengan hasil penelitian lain menunjukkan bahwa pada pasien BPJS, indikator dari mutu pelayanan keperawatan berdampak terhadap kepuasan pasien BPJS. Indikator mutu pelayanan keperawatan tersebut meliputi indikator assurance, empathy, reliability, dan responsiveness [18]. Oleh sebab itu manajemen Rumah Sakit Kabupaten Jember harus memperhatikan setiap mutu pelayanan keperawatan yang diberikan oleh perawat agar kepuasan pasien BPJS meningkat.

Hasil penelitian persepsi umum pasien menunjukkan bahwa menurut 80 pasien $(63,5 \%)$, kualitas pelayanan kesehatan dan kualitas pelayanan keperawatan bagus. Penelitian ini juga menunjukkan bahwa 90 pasien $(71,5 \%)$ setuju untuk merekomendasikan salah satu rumah sakit di Kabupaten Jember kepada e-Journal Pustaka Kesehatan, vol. 8 (no. 2), Mei 2020 keluarga dan teman yang membutuhkan pelayanan kesehatan. Penelitian ini sejalan dengan hasil penelitian lain bahwa terdapat $61,4 \%$ dan $63,9 \%$ pasien menilai kualitas pelayanan kesehatan dan kualitas pelayanan keperawatan sangat baik. Sebanyak 87,9\% pasien juga menyatakan bahwa mereka akan merekomendasikan rumah sakit kepada keluarga dan teman-teman mereka [1].

Pasien akan menunjukkan kepuasan terhadap pelayanan keperawatan yang diterima selama dirawat di rumah sakit apabila kualitas perawatan klinis kualitas kinerja perawat lebih baik [19]. Sebagian besar rumah sakit menggunakan informasi dari hasil kepuasan pasien ini sebagai bagian dari strategi pemasaran mereka [5]. Kepuasan dari pasien dapat digunakan sebagai strategi untuk memperoleh lebih banyak lagi pasien yang setia (loyal) [20]. Salah satu indikator dari loyalitas pasien adalah merekomendasikan pelayanan kepada orang lain. Rekomendasi dari mulut ke mulut yang positif dapat menghemat biaya pemasaran dan efektif untuk membangun pasien yang setia [21]. Peneliti berasumsi bahwa pasien BPJS akan puas terhadap pelayanan keperawatan apabila kualitas perawatan lebih baik dengan memperhatikan penilaian pasien terhadap pelayanan keperawatan, kualitas kinerja perawat yang lebih tinggi dengan meningkatkan kemampuan dan keterampilan dalam merawat dan memberikan pelayanan secara efektif dan efisien kepada pasien, dan lingkungan kerja perawat yang lebih baik dengan cara melakukan komunikasi dan koordinasi antar sesama petugas kesehatan yang lain. Apabila pasien puas terhadap pelayanan keperawatan, maka mereka akan bersedia untuk kembali lagi ke rumah sakit tersebut dan bersedia merekomendasikan rumah sakit tersebut kepada teman-teman dan keluarga jika membutuhkan pelayanan kesehatan.

\section{Simpulan dan Saran}

Gambaran kepuasan pasien BPJS terhadap mutu pelayanan keperawatan di salah satu rumah sakit Kabupaten Jember dapat dikatakan tidak maksimal karena menunjukkan hasil ratarata kepuasan pasien tidak mendekati ke arah nilai maksimal, hanya telah melewati nilai tengah. Kualitas pelayanan kesehatan dan kualitas pelayanan keperawatan bagus. Pasien setuju untuk merekomendasikan salah satu rumah sakit Kabupaten Jember kepada keluarga dan teman yang membutuhkan pelayanan 
kesehatan. Peneliti menyarankan untuk peneliti selanjutnya agar membahas hubungan karakteristik responden dan hubungan indikator yang mempengaruhi kepuasan pasien dengan kepuasan pasien terhadap kualitas pelayanan keperawatan menggunakan kuesioner lain.

\section{Daftar Pustaka}

[1] Karaca A dan Durna Z. 2019. Patient Satisfaction with The Quality of Nursing Care. (October 2017):535-545.

[2] Dzomeku VM, Atinga Ba-Etilayoo, Perekuu T, dan Mantey RE. 2013. In-Patient Satisfaction with Nursing Care: A Case Study at Kwame Nkrumah University of Science and Technology Hospital. International Journal of Research In Medical and Health Sciences. 2(1):1-6.

[3] Counte MA. 2007. Health Care Quality Assessment. Diambil kembali dari Global Health Education Consortium: https://www.cugh.org/sites/default/files/94 Health_Care_Quality_Assessment_FINAL_ 0.pdf [Diakses pada Maret 02, 2019].

[4] Buchanan J, Dawkins P, dan Lindo JL. 2015. Satisfaction with Nursing Care in the Emergency Department of an Urban Hospital in the Developing World: A Pilot Study. International Emergency Nursing. 23(3):218-224.

[5] Laschinger HS, Hall LM, Pedersen C, dan Almost J. 2005. A Psychometric Analysis of The Patient Satisfaction with Nursing Care Quality Questionnaire. Journal of Nursing Care Quality. 20(3):220-230.

[6] Salehi A, Jannati A, Nosratnjad S, dan Heydari L. 2018. Factors Influencing The Inpatients Satisfaction in Public Hospitals: A Systematic Review. Bali Medical Journal. $7(1): 17$.

[7] Peraturan Badan Penyelenggara Jaminan Sosial Kesehatan Nomor 6 Tahun 2018. Administrasi Kepesertaan Program Jaminan Kesehatan. 18 Desember 2018. Berita Negara Republik Indonesia Tahun 2018 Nomor 1666. Jakarta.

[8] Andantika RV. 2016. Perbedaan Mutu Pelayanan Keperawatan pada Pasien BPJS dan Non BPJS di Ruang Rawat Inap Kelas III Rumah Sakit Daerah Balung Kabupaten Jember. Skripsi. Jember: Program Studi Ilmu Keperawatan Universitas Jember.

[9] Maqsood AS, Oweis AI, dan Hasna FS. 2012. Differences Between Patients'
Expectations and Satisfaction with Nursing Care in A Private Hospital in Jordan. International Journal of Nursing Practice. 18(2):140-146.

[10] Jahja Y. 2011. Psikologi Perkembangan. Jakarta: Prenadamedia Group.

[11] Oroh ME, Rompas S, dan Pondaag L. 2014. Faktor-faktor yang Berhubungan dengan Tingkat Kepuasan Pasien Rawat Inap terhadap Pelayanan Keperawatan di Ruang Interna RSUD Noongan. Jurnal Keperawatan. Ejournal Unsrat. 02(02).

[12] Gunarsa S. 2008. Psikologi Perawatan. Jakarta: Gunung Mulia.

[13] Afrillia D. 2018. Menelusuri Hubungan antara Pernikahan dan Kesehatan. Jakarta: Beritagar.id. 12 Februari.

[14] Bauk I, Kadir AR, dan Saleh A. 2013. Hubungan Karakteristik Pasien dengan Kualitas Pelayanan: Persepsi Pasien Pelayanan Rawat Inap RSUD Majene Tahun 2013. Makasar: Universitas Hasanuddin.

[15] Rizal A dan Jalpi A. 2018. Analisis Faktor Internal Penentu Kepuasan Pasien Puskesmas Kota Banjarmasin. Al Ulum Sains dan Teknologi. 4:1-6.

[16] Taufik AA, Pribadi F, dan Handayani SD. 2018. Analysis Effect Service Quality of BPJS Program to Patient Satisfaction Mediated by Medical Performance. International Journal of Management and Economics Invention. 04(05):1759-1765.

[17] Al-Assaf AF. 2009. Mutu Pelayanan Kesehatan: Perspektif Internasional. (M. Fauziah, \& A. Lukman, Penerj.) Jakarta: EGC.

[18] Imelda S. dan Nahrisah E. 2015. Peningkatan Kepuasan Pasien di RSUP Adam Malik Medan (Studi Perbandingan antara Pasien Umum dan Pasien BPJS). Jurnal IImiah AMIK Labuhan Batu. 3(3).

[19] Lake ET, Germack HD, dan Viscardi MK. 2016. Missed Nursing Care is Linked to Patient Satisfaction: a Cross-Sectional Study of US Hospitals. BMJ Qual Saf. 25:535-543.

[20] Pohan IS. 2006. Jaminan Mutu Layanan Kesehatan: Dasar-Dasar Pengertian dan Penerapan. Jakarta: EGC.

[21] Wijaya D. 2014. Model Strategi Switching Barriers untuk Loyalitas Pasien Berbasis Perilaku Caring Perawat. Jurnal Keperawatan Soedirman. 9(2):72-85. 